\title{
Effects of n-propyl gallate on photosynthesis and physiological parameters in Dunaliella salina are affected by stressful conditions
}

\author{
Alireza Einali ${ }^{1 *}$, Mansour Shariati ${ }^{1}$ \\ 'Department of Biology, Faculty of Science, University of Isfahan, Hezarjarib St., Isfahan, Iran. \\ ${ }^{\star}$ Corresponding author: alireza@sci.ui.ac.ir
}

Received: 31 May 2012; Accepted: 20 October 2012

\begin{abstract}
We studied the effects of n-propyl gallate, which is a plastid terminal oxidase inhibitor involved in chlororespiration, on photosynthesis and physiological parameters in Dunaliella salina grown under different salinities and under low or high irradiance using chlorophyll a fluorescence transient measurements and pigment analysis. The inhibitor up to $1 \mathrm{mM}$ had an additive significant effect on the photosynthetic efficiency in the cell suspensions grown under low salinity and irradiance. However, in the presence of high n-propyl gallate concentration (4 mM), there was a negative effect on all physiological aspects. In contrast, this high concentration of the inhibitor could enhance efficiency of electron transport and growth parameters under high irradiance. On the other hand, with salinity increase, the unfavorable effects of high inhibitor concentration on the efficiency of photosystem II were less evident than of low salinity. Interestingly, n-propyl gallate high concentration had a positive effect on fluorescence and on physiological parameters when high salinitiesgrown cells were exposed to high irradiance. The results suggest that there is a rational correlation between increase of salinity and algae ability to bypass n-propyl gallate inhibited plastid terminal oxidase function and also direct influence of its lethal concentration on photosystem II compartment. The ability is especially substantial when the increase of salinity is accompanying high irradiance. Furthermore, these data show that algal responses to inhibitor concentrations are different under various environmental conditions.
\end{abstract}

Keywords: chlorophyll fluorescence, Dunaliella salina, light intensity, photosynthesis, salt stress.

\section{INTRODUCTION}

Stress usually refers to an unfavorable condition in which an external factor exerts undesirable influence on plants, and it can cause the happening of special responses in all physiological levels of an organism (Quiles, 2006; Diaz et al., 2007; Ibanez et al., 2010). Plants have developed individual tolerance mechanisms to cope with the environmental stress during evolutional processes, as the mechanisms are much varied between species and different groups (Quiles, 2006; Diaz et al., 2007). Under environmental stress conditions, such as salinity and high irradiance, plants show the ingenious adaptations at all levels of organization, from morphological to biochemical, molecular, and physiological levels (Diaz et al., 2007). At the biochemical and physiological levels, plants can alter their flow of photosynthetic electron transfer in several ways in order to cope with the stress (Dijkman and Kroon, 2002; Quiles, 2006; Diaz et al., 2007; Gamboa et al., 2009; Ibanez et al., 2010).

In some conditions such as stress, there is an alternative route to the typical electron transport chain, namely chlororespiration, which consists of the electron transfer to an oxygen molecule through the plastoquinone (PQ) pool through a terminal oxidase and the generation of 
a water molecule at the thylakoid stromal side (Bennoun, 1982; Nixon, 2000; Dijkman and Kroon, 2002; Peltier and Cournac, 2002; Rumeau et al., 2007). The existence of such pathway has been molecularly confirmed by the discovery of new molecular components in the thylakoid membranes, including a plastid-encoded $\mathrm{NAD}(\mathrm{P}) \mathrm{H}$ dehydrogenase complex - NDH (Quiles and Cuello, 1998; Rumeau et al., 2005), and a nucleus-encoded plastid terminal oxidase PTOX (Aluru and Rodermel, 2004; Kuntz, 2004).

The PTOX is functionally equivalent to a quinoneoxygen oxidoreductase, which is involved in carotenoid biosynthesis and chlororespiration in algae (Bennoun, 1982; Wang et al., 2009; Cruz et al., 2011) and higher plants (Carol and Kuntz, 2001; Josse et al., 2003; Aluru and Rodermel, 2004). In agreement to PTOX role as a terminal oxidase (Peltier and Cournac, 2002; Kuntz, 2004), it has been supposed that it may act as a safety valve for excess electrons, preventing the over reduction of the electron transport chain (Niyogi, 2000; Rizhsky et al., 2002) and thereby minimizing the aberrant formation of potentially destructive reactive oxygen species (ROS), within the chloroplast (Melis, 1999; Niyogi, 2000).

There is physiological and biochemical evidence indicating that PTOX has a key role in the carotenoid biosynthesis during primary processes of the chloroplast differentiation (Carol and Kuntz, 2001), and plays a critical protective role against stress (Aluru and Rodermel, 2004; Wang et al., 2009). Since it has been confirmed that PTOX plays a role as a terminal oxidase and the carotenoid biosynthesis process is dependent on re-oxidation of the reduced PQ pool (Carol and Kuntz, 2001; Morstadt et al., 2002), the suggested role for PTOX in the latter process is not incompatible. Thus, inhibition of PTOX in both molecular (by mutation) and biochemical (by inhibitor) levels affects plant photosynthesis apparatus, and consequently, plants tolerance under environmental stress conditions (Shahbazi et al., 2007; Gamboa et al., 2009). However, although PTOX in the photosynthetic electron transport chain probably does not play a major role during photosynthesis under optimal conditions (Gamboa et al., 2009), it likely participates to the required flexibility of photosynthetic electron transfer reactions, when photosynthesis operates under unstable environmental conditions.

Dunaliella salina is a unicellular and halo-tolerant green algae that can accumulate a large amount of $\beta$-carotene under different stress conditions (Ben-Amotz and Avron, 1983; Hosseini Tafreshi and Shariati, 2009). In the present study, Dunaliella salina was taken as a model system for examining the effects of n-propyl gallate (PG), an inhibitor of PTOX (Cournac et al., 2000; Kuntz, 2004), on the photosynthetic electron transport of photosystem II (PSII) and physiological parameters under stress caused by salt and high irradiance.

\section{MATERIAL AND METHODS}

Algal cultures and experimental treatments: Dunaliella salina Teod. UTEX 200 was obtained from the UTEX The Culture Collection of Algae at the University of Texas, in Austin. The cells were grown in a culture medium with concentrations of 1,2 and $3 \mathrm{M} \mathrm{NaCl}$ as described by Shariati and Lilley (1994). Cultures were incubated in a culture room at $25^{\circ} \mathrm{C}$ and $70 \mu \mathrm{mol}$ photons $\mathrm{m}^{-2} \mathrm{~s}^{-1}$ of light irradiance under a 16 and 8-hour light/dark photoperiod with a continued shaking (100 rpm). When the cultures containing superior concentrations of $\mathrm{NaCl}$ were at the growth exponential phase, they were transferred to the flasks followed by treatments application. PG (prepared from Fluka company) was applied at five levels of $0.1,0.5,1$, 2 and $4 \mathrm{mM}$ into the flasks (in triplicates), and then they were put at two different light regimes: $70 \mu \mathrm{mol}$ photons $\mathrm{m}^{-2} \mathrm{~s}^{-1}$ as low irradiance (LI) and $400 \mu \mathrm{mol}$ photons $\mathrm{m}^{-2} \mathrm{~s}^{-1}$ as high irradiance (HI). Cultures at the low or high irradiances in the absence of inhibitor served as controls.

Cell counting and pigment analysis: The cell number was determined using a hemocytometer under a light microscope (Schoen, 1988). For chlorophyll and $\beta$-carotene extractions, an aliquot $(1 \mathrm{~mL})$ of algae cell suspension was precipitated by centrifugation at $10,000 g_{n}$ for five minutes, followed by adding $1 \mathrm{~mL}$ of $80 \%$ acetone $(\mathrm{v} / \mathrm{v})$ and centrifuged at $10,000 \mathrm{~g}_{\mathrm{n}}$ for two minutes after an intense vortex. Chlorophyll concentration was spectrophotometrically determined by the method carried out by Arnon (1949). $\beta$-carotene was assayed according to Ben-Amotz and Avoron (1983). $E^{1 \%}{ }_{1 \mathrm{~cm}}$ of 2,273 at $480 \mathrm{~nm}$ was used to calculate $\beta$-carotene concentration.

Oxygen evolution rate: Oxygen evolution by photosynthesis was polarographically measured at $28^{\circ} \mathrm{C}$ using a Clark-type oxygen electrode (Hansatech Instruments $\mathrm{Ltd}$, UK) in a $2 \mathrm{~mL}$ water-jacketed reaction vessel (Delieu and Walker, 1972). The $0_{2}$ electrode was connected to a chart recorder. A projector with a $100 \mathrm{~W}$ lamp was used for illumination, where the white light beam was radiated through a red filter. The red-light beam was projected through a spherical focusing lens (a round-bottom flask filled with water) as required in order to obtain high-light intensity. A light intensity of $400 \mu \mathrm{moL}$ photons $\mathrm{m}^{-2} \mathrm{~s}^{-1}$ was used for measuring oxygen evolution. Before the experiment, algal samples were harvested from suspension by centrifugation 
at 2,000 $g_{n}$ for five minutes and after removal of supernatant, the remaining pellet was re-suspended in a reaction medium containing $0.25 \mathrm{mM} \mathrm{KH}_{2} \mathrm{PO}_{4}, 0.25 \mathrm{mM} \mathrm{K}_{2} \mathrm{HPO}_{4}, 0.2 \mathrm{mM}$ $\mathrm{MgCl}_{2}, 25 \mathrm{mM} \mathrm{NaHCO}{ }_{3}$, and $1 \mathrm{M} \mathrm{NaCl}(\mathrm{pH}=7.5)$. Oxygen evolution rate was monitored in suspensions supplemented with $1 \mathrm{mM} P \mathrm{PG}$ into the oxygen vessel measuring followed by concentrations of $1,2.5,2.75$, and $3 \mathrm{M}$ salinity as salt stress.

Chlorophyll fluorescence measurement: Chlorophyll a fluorescence parameters were measured using the Plant Efficiency Analyzer (Handy PEA fluorimeter, Hansatech Instruments Ltd., Pentney, King's Lynn, Norfolk, England). An aliquot $(1 \mathrm{~mL})$ alga cell suspension was transferred to the glass vials and pre-darkened for ten minutes at room temperature. Chlorophyll a fluorescence induction transient was measured when the vials were exposed to a strong light pulse $\left(3,500 \mu \mathrm{mol}\right.$ photons $\left.\mathrm{m}^{-2} \mathrm{~s}^{-1}\right)$. The data were analyzed using BiolyzerHP3 software (Laboratory of Bioenergetics, University of Geneva, Switzerland) (Strasser et al., 2000). The parameters used in this study are listed in Table 1.

Table 1. OJIP test parameters and expressions.

\begin{tabular}{|c|c|}
\hline Parameters & Description \\
\hline ABS/RC & $\begin{array}{l}\text { Light absorption flux for PSII antenna chlorophylls, } \\
\text { per reaction center (RC) }\end{array}$ \\
\hline Area & $\begin{array}{l}\text { The area above the chlorophyll fluorescence curve } \\
\text { between } \\
F_{0} \text { and } F_{m} \text { (reflecting the size of the plastoquinone } \\
\text { pool) }\end{array}$ \\
\hline $\mathrm{F}_{0}$ & Fluorescence intensity at $50 \mu \mathrm{s}$ ( 0 step) \\
\hline $\mathrm{F}_{\mathrm{J}}$ & Fluorescence intensity at $2 \mathrm{~ms}$ (J step) \\
\hline$F_{1}$ & Fluorescence intensity at 30 ms (I step) \\
\hline $\mathrm{F}_{\mathrm{m}}$ & Maximal fluorescence intensity (P step) \\
\hline $\mathrm{F}_{\mathrm{v}}$ & Maximal variable fluorescence; $F_{v}=F_{m}-F_{0}$ \\
\hline $\mathrm{F}_{v} / \mathrm{F}_{0}$ & $\begin{array}{l}\text { Avalue that is proportional to the activity of } \\
\text { water-splitting complex on the donor side of the PSII }\end{array}$ \\
\hline $\mathrm{F}_{\mathrm{v}} / \mathrm{F}_{\mathrm{m}}$ & $\begin{array}{l}\text { Maximum quantum yield of PSII } \\
F_{\sqrt{ }} / F_{m}=\left[1-\left(F_{0} / F_{m}\right)\right]\end{array}$ \\
\hline $0-J-I-P$ & $\begin{array}{l}\text { Transient fluorescence induction defined by the names } \\
\text { of its intermediate steps ( } 0 \text { is for 'origin' and ' } P \text { ' is for } \\
\text { peak, whereas, } J \text { and I are intermediate steps) }\end{array}$ \\
\hline $\mathrm{PI}_{A B S}$ & Performance index \\
\hline $\mathrm{SFI}_{\mathrm{ABS}}$ & An indicator of PSII 'structure and functioning' \\
\hline$\Phi_{\mathrm{Ro}}$ & $\begin{array}{l}\text { Quantum yield for reduction of end electron acceptors } \\
\text { at the PSI acceptor side (RE) }\end{array}$ \\
\hline$\Psi_{0}$ & Probability that an electron moves further than $Q A$ \\
\hline$\Phi_{\mathrm{Do}}$ & Thermal dissipation yield \\
\hline$\Phi_{\mathrm{E}_{0}}$ & Quantum yield for electron transport (ET) \\
\hline
\end{tabular}

Statistical analysis: All measurements and determinations were conducted in triplicate. Data were expressed as mean \pm standard deviation (SD). The correlation test was applied between the means of some growth parameters, and the correlation coefficient was determined as -0.98 . Statistically significant differences between the means at $p<0.05$ were determined using the analysis of variance (ANOVA) and followed by HolmSidak's test. All analyses were performed using SigmaState 3.0 (Jandel Scientific, San Rafael, California) software.

\section{RESULTS}

Effects of n-propyl gallate on growth kinetics: Cell density in algal cells $1 \mathrm{M}$-LI exposed for 96 hours to 1,2 and $4 \mathrm{mM} \mathrm{PG}$ significantly decreased by about 30,40 and $70 \%$ as compared to control (absence of PG), respectively (Figure 1). However, the highest increase of the cell number was observed at 0.5 $\mathrm{mM} P \mathrm{PG}$ in the algal suspensions. Cell density substantially increased at 0.1 and $1 \mathrm{mM} \mathrm{PG}$ and it was statistically unchanged at 2 and $4 \mathrm{mM} \mathrm{PG}$ with respect to control in algal cells $1 \mathrm{M}-\mathrm{HI}$. There is a gradual decrease in the cell growth, in which about $60 \%$ of the cells died in algal cells $2 \mathrm{M}-\mathrm{LI}$ exposed to $4 \mathrm{mM}$ of the inhibitor. However, in algal cells $2 \mathrm{M}$-HI, cell growth did not considerably change at all PG concentrations excluding 0.5 and $4 \mathrm{mM}$, which increased and decreased separately up to 62 and $53 \%$ as compared to control, respectively. There was a significant decrease in cell density, when algal cells $3 \mathrm{M}$-LI were subjected to 2 and $4 \mathrm{mM} \mathrm{PG}$. Cell growth was also decreased in PG-treated algal cells $3 \mathrm{M}$-HI. At this condition, unlike others, no change in cell density was found at PG concentration of 4 $\mathrm{mM}$ when compared to control.

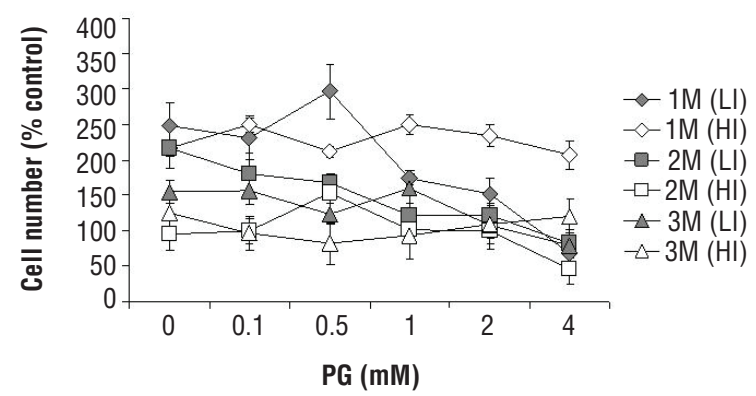

Figure 1. Effects of different PG (n-propyl gallate) concentrations on cell density (number of cell) of Dunaliella salina suspensions grown at 1, 2 and $3 \mathrm{M} \mathrm{NaCl}$ under $\mathrm{LI}$ (Low Irradiance) or $\mathrm{HI}$ (High Irradiance) condition 96 hours after inhibitor application, calculated on the basis of percentage of their values at time 0 . Suspensions grown without PG under $\mathrm{LI}$ or $\mathrm{HI}$ conditions were taken as control. Each point represents the mean value of three separate samples \pm standard deviation. 
Effects of n-propyl gallate on pigment content: Despite the fact that addition of $P G$ up to $0.5 \mathrm{mM}$ showed an increase in chlorophyll content, there was a drastic decrease in algal cells $1 \mathrm{M}-\mathrm{LI}$ subjected for 96 hours to $4 \mathrm{mM} \mathrm{PG}$ (about $40 \%$ compared to control), as seen in Figure 2A. Similar reduction was also found when algal cells $2 \mathrm{M}$-LI were exposed to $4 \mathrm{mM} \mathrm{PG}$. However, addition of $P G$ by 1 to $4 \mathrm{mM}$ showed a positive effect on chlorophyll content in algal cells $1 \mathrm{M}-\mathrm{HI}$, in which it reached $145 \%$ of control at $4 \mathrm{mM} \mathrm{PG}$. In algal cells $2 \mathrm{M}-\mathrm{HI}$, the inhibitor had no effects on chlorophyll content up to $1 \mathrm{mM}$, while 2 and $4 \mathrm{mM}$ PG markedly increased and decreased chlorophyll content up to 127 and $61 \%$ of control, respectively. Similar to algal cells $1 \mathrm{M}-\mathrm{LI}$, an addition of $\mathrm{PG}$ up to $0.5 \mathrm{mM}$ to algal cells $3 \mathrm{M}-\mathrm{LI}$ increased chlorophyll content by $24 \%$ as compared to control. Under such conditions, there was a lower decrease in chlorophyll content at $4 \mathrm{mM} P \mathrm{PG}$ (by $80 \%$ of control) compared to the algal cells 1 and 2 M-LI. In algal cells $3 \mathrm{M}-\mathrm{HI}, \mathrm{PG}$ could noticeably increase chlorophyll content at 1, 2 and $4 \mathrm{mM}$ by 17,34 , and $56 \%$ as compared to control, respectively.

The $\beta$-carotene was affected in the less extent by $P G$ treatment as compared to chlorophyll content. Similar to chlorophyll content, PG resulted in a major
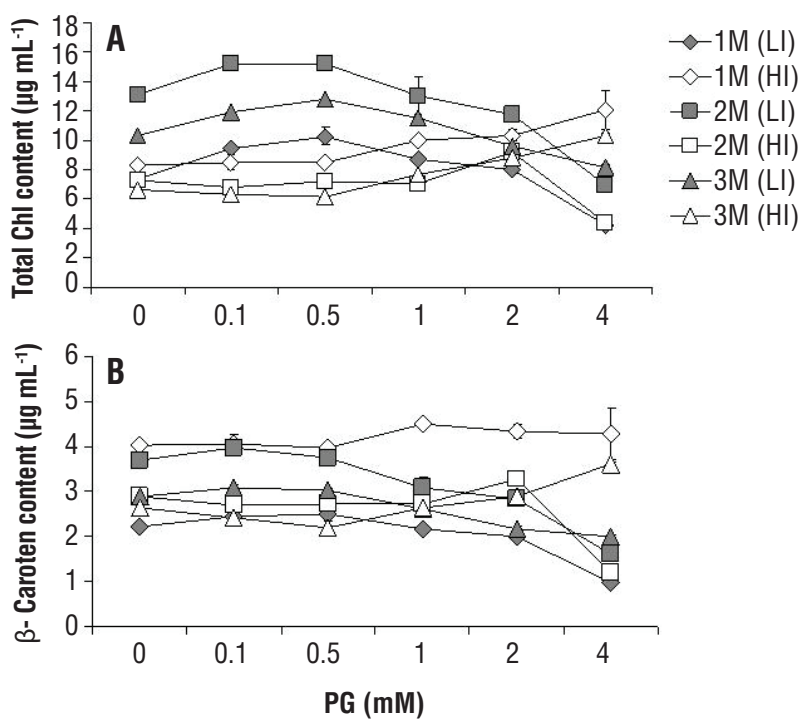

Figure 2. Effects of $P G$ (n-propyl gallate) at varying concentrations on total chlorophyll (A) and $\beta$-carotene (B) content of Dunaliella salina suspensions grown at 1,2 and $3 \mathrm{M}$ $\mathrm{NaCl}$ under LI (Low Irradiance) or HI (High Iradiance) condition 96 hours after inhibitor application. Suspensions grown without $\mathrm{PG}$ under $\mathrm{LI}$ or $\mathrm{HI}$ conditions were taken as control. Data are the means of three separate extractions \pm standard deviation. decrease (by $43 \%$ of control) of $\beta$-carotene content in algal cells $1 \mathrm{M}$-LI, which were subjected to $4 \mathrm{mM} \mathrm{PG}$ (Figure 2B). Nevertheless, there was no or minor change in $\beta$-carotene content in PG-treated algal cells $1 \mathrm{M}$-HI. Experiments on algal cells $2 \mathrm{M}-\mathrm{LI}$ revealed a great negative correlation between $\beta$-carotene content, with concentrations presenting more than $0.1 \mathrm{mM}$ of the inhibitor, where it reached $44 \%$ of control at $4 \mathrm{mM} \mathrm{PG}$. In algal cells $2 \mathrm{M}-\mathrm{HI}$, $\beta$-carotene displayed a similar pattern to the chlorophyll content under the same condition, in which 2 and $4 \mathrm{mM}$ PG obviously increased and decreased such content up to 114 and $42 \%$ of control, respectively. In algal cells $3 \mathrm{M}-\mathrm{LI}$, PG decreased $\beta$-carotene content at 2 and $4 \mathrm{mM}$ by 25 and $30 \%$ as compared to control, respectively. However, in algal cells $3 \mathrm{M}-\mathrm{HI}, 2$ and $4 \mathrm{mM} \mathrm{PG}$ increased $\beta$-carotene content up to 10 and $38 \%$ in comparison to control, respectively.

Changes in photosynthesis by n-propyl gallate under salt stress: As expected, with the increase in salt concentrations, there was a significant decrease in photosynthesis rate (Figure 3). Addition of $1 \mathrm{mM} \mathrm{PG}$ to the measuring vessel of oxygen causes a significant decrease in net photosynthesis at all salinity concentrations. However, it is noteworthy that the rate of decrease is higher in control (1 M salinity), when compared to 2.5 and $2.75 \mathrm{M}$, but not at $3 \mathrm{M}$ salt shock. At $1 \mathrm{M}$ salinity, PG concentration of $1 \mathrm{mM}$ results in the decrease of photosynthesis to an extent of $22 \%$, while the decrease was 15,13 and $84 \%$ for $2.5,2.75$ and $3 \mathrm{M}$ salt shock, respectively (Figure 3 ).

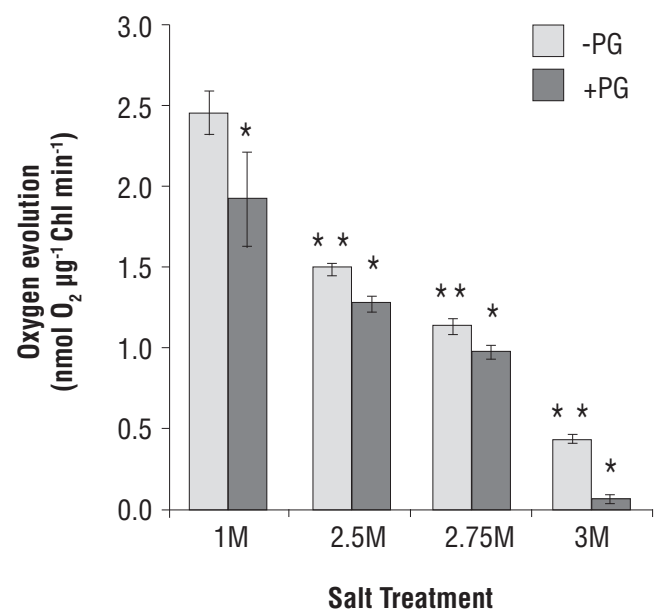

Figure 3. Photosynthetic oxygen evolution rate measured at $28^{\circ} \mathrm{C}$ using a Clark-type oxygen electrode in Dunaliella salina under salt shock. Each value is the mean \pm standard deviation of three separate measurements. Single asterisks indicate significant differences in the presence of the inhibitor versus control (absence of the inhibitor), and double asterisks display significant values in various salinities against control ( $1 \mathrm{M}$ salinity) at $\mathrm{p}<0.05$. 
Influence of n-propyl gallate on chlorophyll a fluorescence transient curves: To further study the effects of $P G$ on the photosynthetic electron transport and $P Q$ pool, the fast chlorophyll a fluorescence transients (OJIP) in D.salina exposed 96 hours to different PG concentrations under salt and high irradiance stresses were measured. In algal cells 1 and $2 \mathrm{M}-\mathrm{LI}, \mathrm{PG}$ concentrations of 0.1 and $0.5 \mathrm{mM}$ showed the highest $\mathrm{J}, \mathrm{I}$, and $\mathrm{P}$ levels compared to control (Figures $4 \mathrm{~A}$ and $\mathrm{C}$ ). This means that the algal suspensions under the condition have higher electron transfer content to $Q_{A}$ (J level), higher electron transfer potential to the $P Q$ pool (I level), and more traffic jam on the electron acceptor side of PSI (P level). Chlorophyll a fluorescence transients gradually

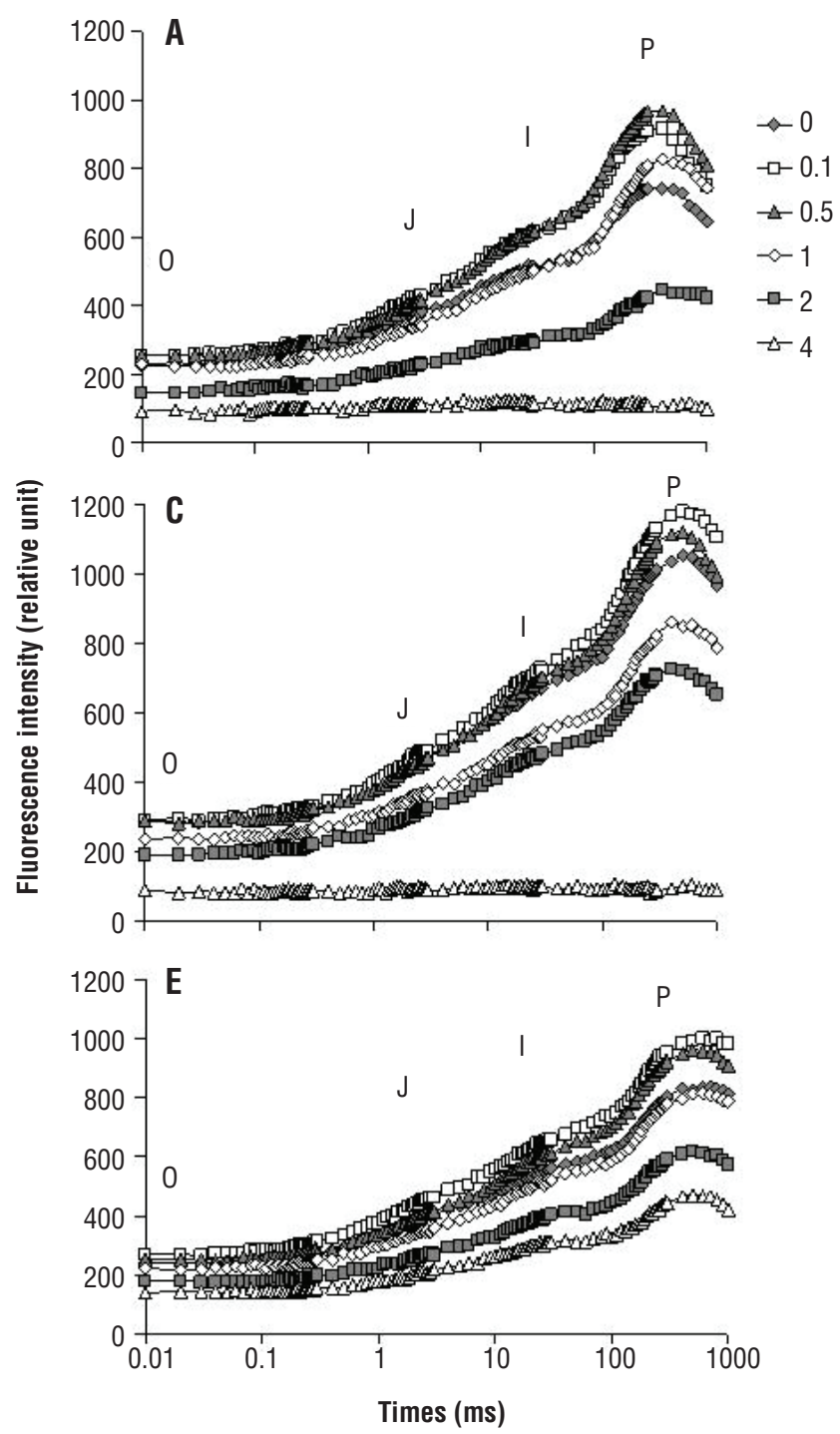

decreased at $P G$ concentrations in more than $1 \mathrm{mM}$ and almost reached a plateau at $4 \mathrm{mM}$ (Figures $4 \mathrm{~A}$ and $\mathrm{C}$ ). No obvious change was found in the original fluorescence transients when algal cells 1 and $2 \mathrm{M}-\mathrm{HI}$ were subjected to $\mathrm{PG}$ concentrations up to $2 \mathrm{mM}$ (Figures 4B and D). However, the chlorophyll fluorescence transient declined at $4 \mathrm{mM} P \mathrm{PG}$. Fluorescence rise curve was higher at $0.1,0.5$ and $1 \mathrm{mM} \mathrm{PG}$ as well as control in algal cells $3 \mathrm{M}-\mathrm{LI}$ (Figure 4E). This suspension showed an electron transport capacity in the presence of $4 \mathrm{mM}$ of the inhibitor, although that is much lower than other fields (Figure 4E). However, algal cells $3 \mathrm{M}-\mathrm{HI}$ subjected to 2 and $4 \mathrm{mM}$ of the inhibitor displayed the highest fluorescence rise relative to other concentrations (Figure 4F).
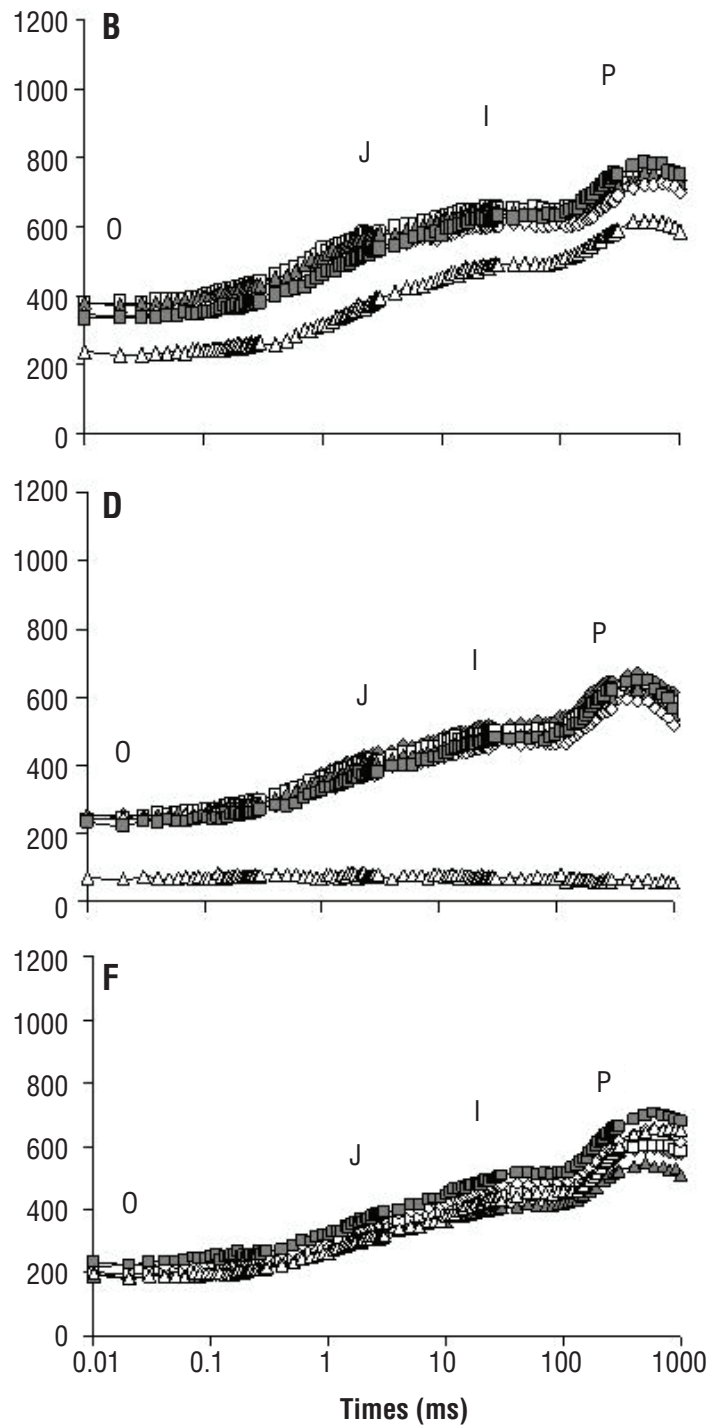

Figure 4. Chlorophyll a fluorescence transient curve of Dunaliella salina grown at 1, 2 and $3 \mathrm{M} \mathrm{NaCl}$ under LI (Low Irradiance) or HI (High Irradiance) conditions subjected to PG (n-propyl gallate) concentrations of 0.1, 0.5, 1, 2 and $4 \mathrm{mM}$ after 96 hours of inhibitor treatment. Suspensions grown without PG under LI or HI conditions were taken as controls. (A, C, E) Algal suspensions grown at 1, 2 and $3 \mathrm{M}$ salinity under $\mathrm{LI}$, and (B, D, F) algal suspensions grown at 1, 2 and $3 \mathrm{M}$ salinity under HI condition, respectively. 
Effects of n-propyl gallate on efficiency of electron transport flow within photosystem II: Data analysis obtained from OJIP test revealed that the efficiency of the water splitting complex $\left(F_{\sqrt{ }} / F_{0}\right)$, quantum yield for reduction of end electron acceptors at the PSI acceptor side $\left(\Phi_{\mathrm{RO}}\right)$, oxidation content of $Q_{A}{ }^{-}$to $Q_{A}\left(\Psi_{0}\right)$, quantum yield of electron transport $\left(\Phi_{E_{0}}\right)$, and maximum efficiency of PSII $\left(F_{V} / F_{m}\right)$ parameters markedly decreased when algal cells $1 \mathrm{M}$-LI were subjected to $4 \mathrm{mM} P \mathrm{PG}$ (Figures $5 \mathrm{~A}$ to $\mathrm{E}$ ). Algal cells $2 \mathrm{M}$-LI subjected to $4 \mathrm{mM}$ PG presented almost a similar pattern to $1 \mathrm{M}$-LI (Figures 5A to E). In addition, thermal dissipation yield $\left(\Phi_{D_{0}}\right)$ (Figure $\left.5 F\right)$ and light absorption flux (for PSII antenna chlorophylls) per reaction center (ABS/ RC) (Figure 6A) increased considerably in both 1 and 2 M-LI exposed to $4 \mathrm{mM}$ of the inhibitor.

Furthermore, in these suspensions, the size of $P Q$ pool index (Area), PSII structure and functioning indicator
$\left(\mathrm{SFI}_{\mathrm{ABS}}\right)$, and performance index $\left(\mathrm{PI}_{\mathrm{ABS}}\right)$ were not detectable in the presence of $4 \mathrm{mM} \mathrm{PG}$ (Figures $6 \mathrm{~B}$ to $\mathrm{D}$ ). In contrast to algal cells $1 \mathrm{M}-\mathrm{LI}, \mathrm{PG}$ concentrations of 2 and $4 \mathrm{mM}$ increased parameters related to the efficiency of electron transport of PSII and correspondingly decreased $\Phi_{D_{0}}$ and $\mathrm{ABS} / \mathrm{RC}$ in algal cells $1 \mathrm{M}-\mathrm{HI}$ (Figures 5 and 6 ).

Similar results were obtained when algal cells $2 \mathrm{M}-\mathrm{HI}$ were assayed, with the difference that only PG concentration of $2 \mathrm{mM}$ could improve the efficiency of electron transport, differently from $4 \mathrm{mM}$ that could not (Figures 5 and 6 ). Experiments on algal cells $3 \mathrm{M}-\mathrm{LI}$ illustrated that $P G$ concentration of $4 \mathrm{mM}$ does not have a significant effect on the fluorescence parameters (Figure 5). However, a pronounced increase was found for the values of fluorescence related to the PSII efficiency, when algal cells $3 \mathrm{M}-\mathrm{HI}$ were exposed to $4 \mathrm{mM} \mathrm{PG}$ (Figures 5 and 6).
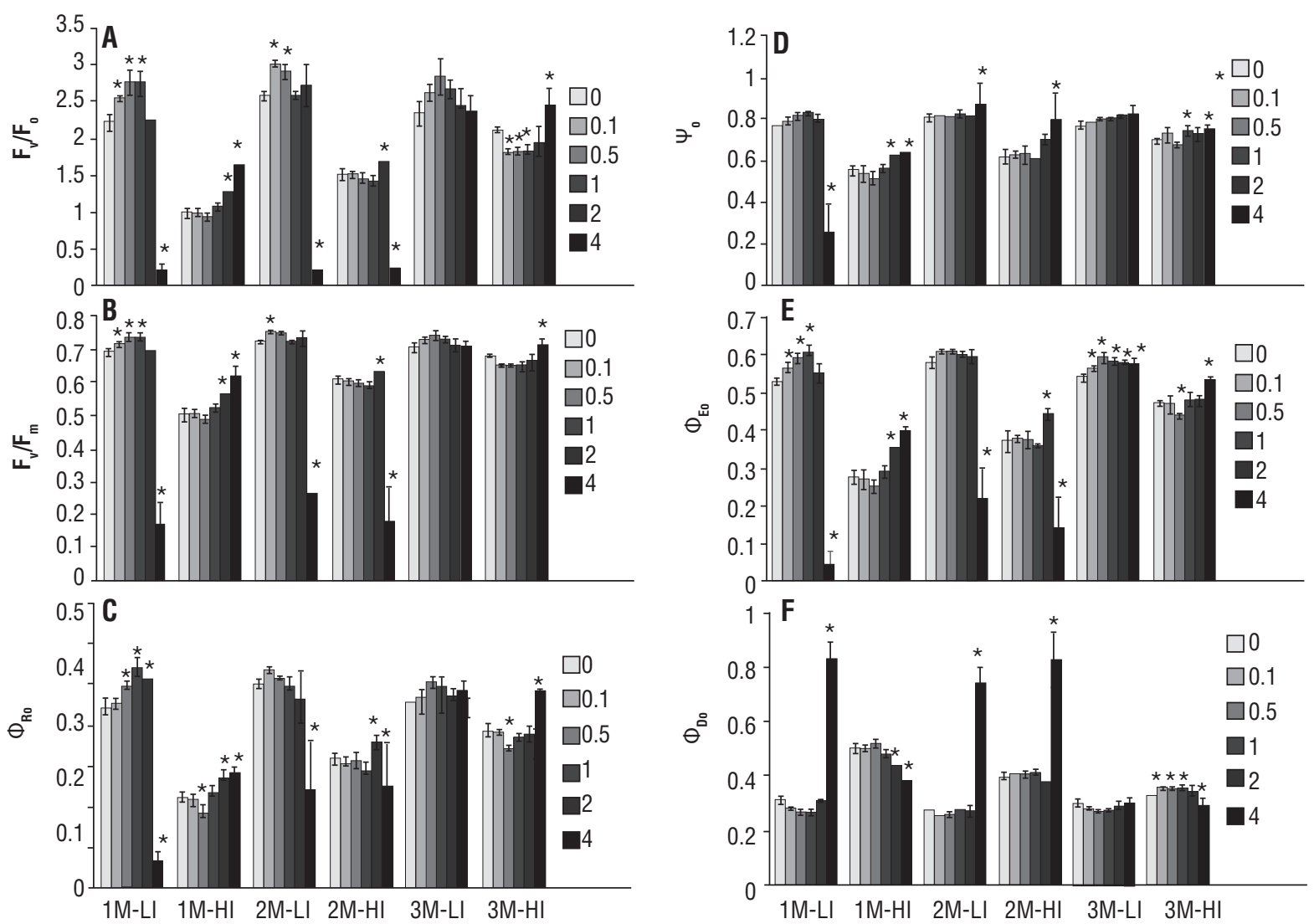

Figure 5. Effect of $P G$ (n-propyl gallate) at $0.1,0.5,1,2$ and $4 \mathrm{mM}$ concentrations on $(A)$ oxygen evolving complex activity $\left(F_{v} / F_{0}\right),(B)$ maximum quantum yield of PSII $\left(F_{V} / F_{m}\right),(C)$ quantum yield for reduction of end electron acceptors at the PSI acceptor side $\left(\Phi_{R_{0}}\right)$, (D) efficiency of electron transfer from $Q_{A}{ }^{-}$to $Q_{B}\left(\psi_{0}\right),(E)$ electron transport yield $\left(\Phi_{E_{0}}\right)$, and $(F)$ thermal dissipation yield $\left(\Phi_{D_{0}}\right)$ in Dunaliella salina suspensions grown at 1, 2 and $3 \mathrm{M} \mathrm{NaCl}$ under LI (Low Irradiance) or HI (High Irradiance) conditions after 96 hours of inhibitor application. Suspensions grown without PG under $\mathrm{LI}$ or $\mathrm{HI}$ conditions were taken as Controls. The bars show standard deviation of the means of three separate experiments. Asterisks representing significant values in the presence of $P G$ versus control (absence of $P G$ ) at $p<0.05$. 

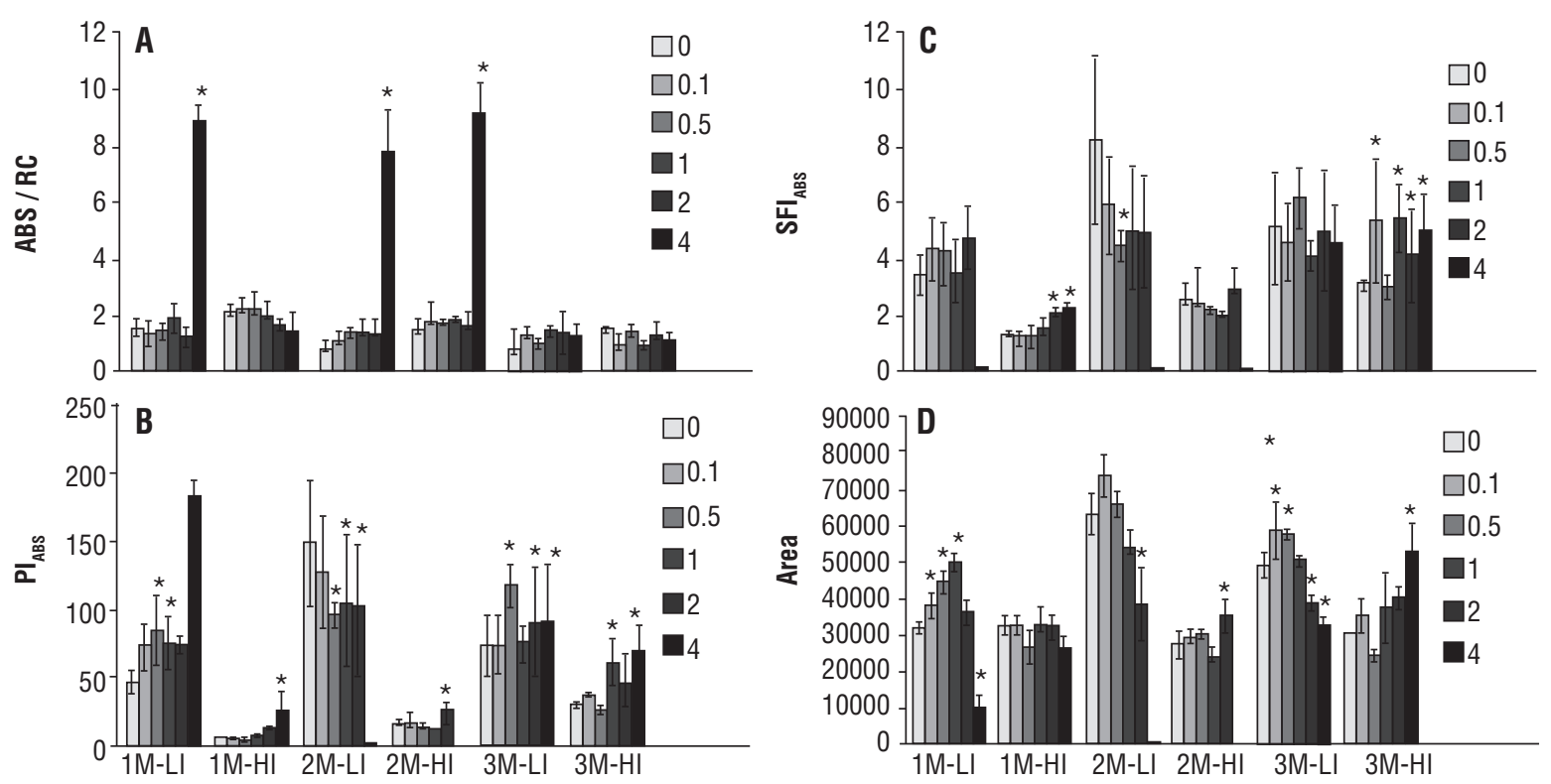

Figure 6. Changes in the amount of light absorption per total number of active reaction center (A), performance index (B), structure and functioning of photosystem II (C), and the area above the chlorophyll fluorescence curve between $F_{0}$ and $F_{m}(D)$ in Dunaliella salina suspensions grown at 1, 2 and $3 \mathrm{M} \mathrm{NaCl}$ under LI (Low Irradiance) or HI (High Irradiance) conditions subjected to different inhibitor concentrations $(0.1,0.5,1,2$ and $4 \mathrm{mM})$ after 96 hours of PG (n-propyl gallate) application. Suspensions grown without PG under LI or HI conditions were taken as Controls. The values are means \pm standard deviation (SD) from triplicate independent measurements. Asterisks represent significant values in the presence of different PG concentrations as compared to control (without $P G$ ) at $p<0.05$.

\section{DISCUSSION}

Photosynthetic electron transport system, as well as pigment content were affected by $P G$ in Dunaliella salina under stress conditions. Addition of $P G$ up to $0.5 \mathrm{mM}$ in algal cells $1 \mathrm{M}-\mathrm{LI}$ had a positive effect on both photosynthesis and physiological parameters, including cell growth and pigment content, demonstrating that $P G$ in the concentration range acts as a protector of the photosynthesis apparatus. It is in agreement to previous reports that $P G$ at low concentrations inhibits D1 protein degradation (Elich et al., 1997). These data are also consistent with Maksymiec et al. (2007), who found that $P G$ at low concentrations can enhance maximum yield of PSII in Arabidopsis. However, addition of the inhibitor at concentrations higher than $0.5 \mathrm{mM}$ had no significant effects on fluorescence parameters as well as pigment content, while at $4 \mathrm{mM}$ $P G$, there was substantial decline at all physiological parameters. This can be due to a significant decrease of oxygen evolving complex $\left(\mathrm{F}_{\mathrm{v}} / \mathrm{F}_{0}\right)$ activity.

Furthermore, drastic decrease of maximum quantum yield $\left(\mathrm{F}_{v} / \mathrm{F}_{\mathrm{m}}\right)$, structure and functioning indicator $\left(\mathrm{SFI}_{\mathrm{ABS}}\right)$ of PSIl and performance index $\left(\mathrm{PI}_{\mathrm{ABS}}\right)$ at $\mathrm{PG}$ concentration of
$4 \mathrm{mM}$ could also be caused by damage to reaction centers or non-photochemical quenching (Maxwell and Johnson, 2000). The thermal dissipation yield $\left(\Phi_{D_{0}}\right)$ was much higher at $P G$ concentration of $4 \mathrm{mM}$ when compared to control, expressing that almost all the excessive light energy was dissipated as heat (Figure 5F). Nonetheless, in spite of the decrease in the efficiency of oxygen evolving complex on the donor side of PSII $\left(\mathrm{F}_{\mathrm{v}} / \mathrm{F}_{0}\right)$ in algal cells 2 $\mathrm{M}-\mathrm{LI}$ exposed to $4 \mathrm{mM} P \mathrm{PG}$, oxidation content of $Q_{A}{ }^{-}\left(\Psi_{0}\right)$ did not reduce (Figure $5 A$ and $D$ ). It may indicate that $\mathrm{F}_{v} / \mathrm{F}_{0}$ and $\Psi_{0}$ parameters are the most sensitive and resistant components in the photosynthetic electron transport chain in the presence of high PG concentration, respectively. In agreement to these results, it has been previously confirmed that the $F_{v} / F_{0}$ parameter is the most sensitive component of PSII under undesirable conditions (Fricke and Peters, 2002).

In contrast to algal cells $1 \mathrm{M}-\mathrm{LI}$, addition of $\mathrm{PG}$ from 1 to $4 \mathrm{mM}$, in algal cells $1 \mathrm{M}-\mathrm{HI}$ enhanced efficiency of electron transport and chlorophyll biosynthesis as compared to control. This discrepancy can be explained by comparing OJIP curves and content of the pigments (Figures $4 \mathrm{~B}$ and 2). An increased $\mathrm{J}$ level is an excellent indicator of a more reduced $P Q$ pool and 
a more considerable primary electron acceptor of PSII $\left(Q_{A}{ }^{-}\right)$accumulation under light excitation (Haldimann and Strasser, 1999). This means that electron transfer between $P Q$ pool and the acceptor side of PSI was diminished under $\mathrm{HI}$, while $P Q$ pool was fully reduced versus $\mathrm{LI}$ condition. The remark could express that under $\mathrm{HI}$ condition, chlororespiration process stopped as a result of PTOX inhibition by PG and consequently there is an accumulation of more pronounced primary electron acceptor of $P S I I\left(Q_{A}{ }^{-}\right)$. Besides, $\beta$-carotene did not significantly change and, as a result, the maintenance of $\beta$-carotene results in the protection and improvement preservation of chlorophyll, as well as its biosynthesis under probable oxidative stress caused by high PG concentration. Therefore, under the condition, PTOX has no role in the carotenoid biosynthesis. The suggestion is supported by a study showing that the carotenoid biosynthesis pathway in tomato mutants in the absence of PTOX under strong light is not limited (Shahbazi et al., 2007).

In addition to fluorescence parameters, there was a severe increase in cell mortality and a meaningful decrease in pigment content in the presence of $4 \mathrm{mM}$ of the inhibitor. For the reason that PTOX has a role in the chloroplast biogenesis (Shahbazi et al., 2007) therefore, the high concentration could block PTOX and could cause arrest chloroplast biogenesis. Alternatively, this event might be due to a formation of ROS. The evidence for the latter suggestion comes from the fact that PTOX has an important role in the carotenoid biogenesis (Bennoun, 2001; Carol and Kuntz, 2001). Thus, with carotenoid biosynthesis blockage, ROS can be formed and cause damage to the chlorophyll and photosynthesis apparatus.

However, our data suggest that the significant decrease in all physiological parameters at PG concentration of $4 \mathrm{mM}$ is not just due to chlorophyll decline (Figure 2A). Besides, Elich et al. (1997) reported that PG at high concentrations acts as a strong inhibitor of light harvesting complex II (LHCII) and to some extent PSII core protein phosphorylation. Inhibition of LHCII phosphorylation could result in imbalance in excitation rates of PSII and PSI (Allen and Forsberg, 2001) and in oxidative stress. Thus, it seems that high concentration of PG could affect PSII directly by influencing its components.

With an increase in salinity, negative effects of $P G$ high concentration on the fluorescence parameters was partly reduced (Figure 5). Although the decrease was not significant, it was very important for understanding the effects on photosynthetic apparatus. It might be attributed to the fact that Dunaliella salina tolerance enhanced with increase of salinity, which is supported by some evidence, including that the decrease of photosynthesis made by addition of $1 \mathrm{mM} \mathrm{PG}$ is minor at 2.5 and $2.75 \mathrm{M}$ salinities unlike $1 \mathrm{M}$ (control), as shown in Figure 3. Another evidence is by comparing electron transport flows in algal cells grown under $\mathrm{HI}$ and $\mathrm{LI}$ conditions indicating that with increase of salinity, the damaging effects of $\mathrm{HI}$ on photosynthesis apparatus have decreased (Figure 5). Therefore, at $2 \mathrm{M}$ salinity under LI condition, $P G$ concentration of $4 \mathrm{mM}$ had a lower negative effect on fluorescence parameters and growth kinetics in comparison with $1 \mathrm{M}$ salinity.

These events can be such interpreted that under high salinity due to the existence of probable alternative pathway and higher tolerance of Dunaliella salina, the negative effect of high concentrations of PG has diminished. It might indicate that PTOX may have a multiple role, and it is conceivable that the relative importance of a given role difference depends on the environmental condition. In other words, PTOX may play a regulatory role rather than act as a safety valve in the protection of the photosynthetic apparatus in Dunaliella salina. The latter suggestion is supported by a report expressing that PTOX does not act as a stress-induced safety valve in the protection of the photosynthetic apparatus of Arabidopsis (Rosso et al., 2006). However, confirmation of the hypothesis needs more investigations and it remains to be elucidated.

In addition, it has been previously reported that when Dunaliella salina increases with salinity, LHCII phosphorylation level enhances (Liu and Shen, 2006). On the other side, it is confirmed that PG at high concentrations inhibits LHCII phosphorylation (Elich et al., 1997), which causes a decline in cyclic electron flow around PSI and consequently, maintenance of electron transport capacity of PSII. Therefore, with increase of salinity under LI and particularly $\mathrm{HI}$ conditions, high concentrations of the inhibitor not only do not have a negative effect, but also could improve efficiency of PSII by maintenance of electron transport flow between two photosystems. It has also been shown that the role of PTOX in stress can have intensity or infirmity and also be different in various species (Gamboa et al., 2009). Therefore, it can be resulted from the data that in Dunaliella salina there are several responding options to $P G$ concentrations under several environmental conditions.

In summary, the results suggest that there is a logical correlation between the increase of salinity and alga ability to bypass PG inhibited PTOX function and or 
direct damage of the inhibitor to PSII components. The algae ability is particularly considerable, when increase of salinity is accompanying high irradiance. Also, effect of $P G$ on photosynthesis and physiological parameters in Dunaliella salina has high variation under various conditions, and it depends on quality and quantity of stress inasmuch as algae displays different responses to $P G$ under various environmental conditions. In other words, responses of algae to the inhibitor might depend on the stress situation.

Acknowledgements: We thank the Deputy of Education and Office of Graduate Studies at the University of Isfahan for their financial support to the study in the form of grant.

\section{REFERENCES}

Allen JF, Forsberg J (2001) Molecular recognition in thylakoid structure and function. Trends Plant Sci. 6:317-326.

Aluru MR, Rodermel SR (2004) Control of chloroplast redox by the IMMUTANS terminal oxidase. Physiol. Plant. 120:4-11.

Arnon D (1949) Copper enzymes in isolated chloroplasts: polyphenoloxidase in Beta vulgaris. Plant Physiol. 24:1-15.

Ben-Amotz A, Avron M (1983) On the factors which determine massive $\beta$-Carotene accumulation in the halo-tolerant alga Dunaliella bardawil. Plant Physiol. 72:593-597.

Bennoun $P$ (1982) Evidence for a respiratory chain in the chloroplast. Proc. Natl. Acad. Sci. USA. 79:4352-4356.

Bennoun P (2001) Chlororespiration and the process of carotenoid biosynthesis. Biochim. Biophys. Acta 1506:133-142.

Carol P, Kuntz M (2001) A plastid terminal oxidase came to light: implications for carotenoid biosynthesis and chlororespiration. Trends Plant Sci. 6:31-36.

Cournac L, Redding K, Ravenel J, Rumeau D, Josse EM, Kuntz M, Peltier G (2000) Electron flow between photosystem II and oxygen in chloroplasts of photosystem I-deficient algae is mediated by a quinol oxidase involved in chlororespiration. J. Biol. Chem. 275:17256-17262.

Cruz S, Goss R, Wilhelm C, Leegood R, Horton P, Jakob T (2011) Impact of chlororespiration on non-photochemical quenching of chlorophyll fluorescence and on the regulation of the diadinoxanthin cycle in the diatom Thalassiosira pseudonana. J. Exp. Bot. 62:509-519.

Delieu T, Walker DA (1972) An improved cathode for measurement of photosynthetic oxygen evolution by isolated chloroplasts. New Phytol. 71:201-225.

Diaz M, Haro VD, Munoz M, Quiles MJ (2007) Chlororespiration is involved in the adaptation of Brassica plants to heat and high light intensity. Plant Cell Environ. 30:1578-1585.

Dijkman NA, Kroon BMA (2002) Indications for chlororespiration in relation to light regime in the marine diatom Thalassiosira weissflogii. J. Photoch. Photobio. B. 66:179-187.

Elich TD, Edelman M, Mattoo AK (1997) Evidence for light-dependent and light independent protein dephosphorilation in chloroplasts. FEBS Lett. 411:236-238.
Fricke W, Peters WS (2002) The biophysics of leaf growth in salt-stressed barley. A study at the cell level. Plant Physiol. 129:374-388.

Gamboa J, Munoz M, Quiles MJ (2009) Effects of antimycin A and npropyl gallate on photosynthesis in sun and shade plants. Plant Sci. 177:643-647.

Haldimann P, Strasser RJ (1999) Effects of anaerobiosis as probed by the polyphasic chlorophyll a fluorescence rise kinetic in pea (Pisum sativum L.). Photosynth. Res. 62:67-83.

Hosseini Tafreshi A, Shariati M (2009) Review: Dunaliella biotechnology: methods and applications. J. Appl. Microbiol. 107:13-35.

Ibanez H, Ballester A, Munoz R, Quiles MJ (2010) Chlororespiration and tolerance to drought, heat and high illumination. J. Plant Physiol. 167:732-738.

Josse EM, Simkin AJ, Gaffe J, Laboure AM, Kuntz M (2003) In vitro characterization of plastid terminal oxidase (PTOX). Eur. J. Biochem. 270:3787-3794.

Kuntz M (2004) Plastid terminal oxidase and its biological significance. Planta 218:896-899.

Liu XD, Shen YG (2006) Salt shock induces state II transition of photosynthetic apparatus in dark-adapted Dunaliella salina cells. Environ. Exp. Bot. 57:19-24.

Maksymiec W, Wojcik M, Krupa Z (2007) Variation in oxidative stress and photochemical activity in Arabidopsis thaliana leaves subjected to cadmium and excess copper in the presence or absence of jasmonate and ascorbate. Chemosphere 66:421-427.

Maxwell K, Johnson NG (2000) Chlorophyll fluorescence-a practical guide. J. Exp. Bot. 51:659-668.

Melis A (1999) Photosystem II damage and repair cycle in chloroplasts: what modulates the rate of photodamage in vivo. Trends Plant Sci. 4:130-135.

Morstadt L, Graber P, De Pascalis L, Kleinig H, Speth V, Beyer P (2002) Chemiosmotic ATP synthesis in photosynthetically inactive chromoplasts from Narcissus pseudonarcissus L. linked to a redox pathway potentially also involved in carotene desaturation. Planta 215:134-140.

Nixon PJ (2000) Chlororespiration. Philos. T. R. Soc. B. 355: 1541-1547.

Niyogi KK (2000) Safety valves for photosynthesis. Curr. Opin. Plant Biol. 3:455-460.

Peltier G, Cournac L (2002) Chlororespiration. Annu. Rev. Plant Biol. 53:523-550.

Quiles MJ (2006) Stimulation of chlororespiration by heat and high light intensity in oat plants. Plant Cell Environ. 29:1463-1470.

Quiles MJ, Cuello J (1998) Association of Ferredoxin-NADP oxidoreductase with the chloroplastic pyridine nucleotide dehydrogenase complex in barley leaves. Plant Physiol. 117:235-244.

Rizhsky L, Hallak-Herr E, Van Breusegem F, Rachmilevitch S, Barr JE, Rodermel S, Inze D, Mittler R (2002) Double antisense plants lacking ascorbate peroxidase and catalase are less sensitive to oxidative stress than single antisense plants lacking ascorbate peroxidase or catalase. Plant J. 32:329-342.

Rosso D, Ivanov AG, Fu A, Geisler-Lee J, Hendrickson L, Geisler M, Stewart G, Krol M, Hurry V, Rodermel SR, Maxwell DP, Huner (2006) IMMUTANS does not act as a stress-induced safety valve in the protection of the photosynthetic apparatus of Arabidopsis during steady-state photosynthesis. Plant Physiol. 142:574-585. 
Rumeau D, Becuwe-Linka N, Beyly A, Louwagie M, Garin J, Peltier G (2005) New subunits NDH-M, $-\mathrm{N}$, and -0 , encoded by nuclear genes, are essential for plastid Ndh complex functioning in higher plants. Plant Cell 17:219-232.

Rumeau D, Peltier G, Cournac L (2007) Chlororespiration and cyclic electron flow around PSI during photosynthesis and plant stress response. Plant Cell Environ. 30:1041-1051.

Schoen M (1988) Cell counting. In: Lobban C, Champan D, Kermer BP (eds), Experimental Phycology, pp. 16-22. Cambridge University Press, Cambridge.

Shahbazi M, Gilbert M, Laboure AM, Kuntz M (2007) Dual role of the plastid terminal oxidase in tomato. Plant Physiol. 145:691-702.
Shariati M, Lilley McC (1994) Loss of intracellular glycerol from Dunaliella by electroporation at constant osmotic pressure: Subsequent restoration of glycerol content and associated volume changes. Plant Cell Environ. 17:1295-1304.

Strasser RJ, Srivastava A, Tsimilli-Michael M (2000) The fluorescence transient as a tool to characterize and screen photosynthetic samples. In: Yunus M, Pathre U, Mohanty P (eds), Probing Photosynthesis: Mechanisms, Regulation and Adaptation, pp. 445-483. Taylor and Francis, London.

Wang J, Sommerfeld M, Hu Q (2009) Occurrence and environmental stress responses of two plastid terminal oxidases in Haematococcus pluvialis (Chlorophyceae). Planta 230:191-203. 